sympathy, common sense, and good manners of medicinenot completely, perhaps not even most of the time, but certainly far too often. This too, we must recognise, is a problem more of hospital medicine than of general practice and more of teaching hospital medicine than of general hospital medicine. Thus as doctors we may seem to dictate when we should discuss, to dominate when we should defer, and to represent an establishment which is all too readily portrayed as insensitive and self-satisfied.

The second broad area of legitimate interest is the status of illness or being ill. Who takes decisions at the boundary where health stops and illness begins? Surely this time Mr Kennedy has his balance wrong. Most doctors-and, in particular, general practitioners-feel that routine decisions over, for example, whether a patient is able to work, whether he needs prescribed medicine, or whether referral to hospital is appropriate are already matters where it is the patient and public and not the doctor who plays the major part in determining what happens at a consultation. As a corollary, is it not time for doctors to complain more effectively about the substantial numbers of patients who persistently refuse to take responsibility for the care of minor and self-limiting illness and persistently disregard health warnings ? Often it is the pressures of quantity and nature of demand that wear doctors down to practising quick, opportunist, or impersonal medical care. If ever politicians could persuade the public to take a more realistic appreciation of the limitations which doctors face in attempting to explain, prevent, and abort every symptom experienced, then the necessary time to develop the better understanding between public and profession would be more readily found. There is little hope of relying on our politicians, however (see p 1662).

Lastly, Mr Kennedy has returned to the central problem of public accountability of monopolistic professional groups. Kennedy is only too right about the difficulties which face patients wanting to make complaints about what has or has not been done to them. He is, however, naive if he believes that doctors are unaffected by threats of inquiries into their professional work. The encouragement of more intervention by courts and lawyers in the relations between doctors and patients will not be seen by doctors as a constructive solution to a real problem. We all know-as Mr Kennedy surely does too-how poorly litigation correlates with fairness or even justice. Patients rarely complain when they have had a truly bad deal, and often when they do complain their complaints reflect factors extraneous to the medical care they have received. Contrary to what Mr Kennedy says, most doctors already value the benefits of intraprofessional audit; where it is realistic and sensitive they will co-operate in it, learn from it, and change their practice accordingly. But when it is the thin edge of the wedge of the control of professional judgment by political pressure, the response is clearly going to be more guardedand that is the response $\mathrm{Mr}$ Kennedy has sensed.

Despite our caveats, Mr Kennedy has stimulated many doctors and patients into looking seriously at important questions of widespread interest and sometimes concern. Some agree with most of what he has said; others have rejected much or all of it. Whether the public or the profession is more responsible for the problems $\mathrm{Mr}$ Kennedy has identified can and should be debated. If each suspects the other, unless one is grossly at fault, the best solution is probably to proceed cautiously rather than precipitately. Even $\mathrm{Mr}$ Kennedy stops short of accusing the medical profession of "anything sinister." Perhaps he will accept that within its walls a substantial reordering is taking place through debate within specialist groups, through continuous restructuring of undergraduate education, and through a steady upgrading of the quality and requirements of postgraduate training. $\mathrm{He}$ should be assured that in general doctors have retained their motivation to provide a true service-but it is now up to those same doctors to reassure the public by their everyday actions. Anything less may be seen as special pleading.

\section{Unquiet sleep}

About one in every 40 persons $^{1}$ walks in his or her sleep; the prevalence is higher in children than in adolescents or adults. Night terrors, in which the sleeper is greatly agitated, moves around restlessly, and may be hallucinated but then returns to sleep and has no recollection of the event, also occur mostly in childhood. Electroencephalographic recordings at night $^{2} 3$ have shown that both these phenomena occur characteristically in slow-wave (stages 3 and 4) sleep, one to three hours after the onset of sleep.

Sleepwalking and night terrors are known to run in families. A study of twins found that concordance was six times more common in monozygotic than in dizygotic twins, supporting a genetic mechanism. ${ }^{4} \mathrm{~A}$ recent investigation of 52 subjects has shown how frequently other members of the family are affected. ${ }^{5}$ In $80 \%$ of the sleepwalkers and $96 \%$ of those suffering from night terrors a first-degree, second-degree, or third-degree relative had one or both of these conditions. The familial pattern suggests a common physiological basis to the two conditions-a view supported by electroencephalographic studies-with night terrors representing the more extreme form. Probably both phenomena arise from the same basic neurophysiological disorder, partly genetically determined. Whether the disorder causes symptoms will depend on the degree of genetic liability and, in some cases, on the presence of stress. The gradual reduction in frequency of manifestation of the disorder with age seems likely to be due to maturation of the nervous system and the development of psychological coping mechanisms.

Lady Macbeth, probably the best-known fictional example of somnambulism, was a guilt-ridden woman whose nocturnal obsessional handwashing was closely related to the life stresses she brought on herself by her ambitious personality. How commonly is sleepwalking associated with stress and psychological disturbance? Studies of attenders at hospital clinics, who may well not be representative of those seen in general practice, suggest that associated psychiatric problems are more common in adults than in children; when they occur they are usually of neurotic type with depression and anxiety predominating. ${ }^{6}$ Most adult sleepwalkers $\left(81 \%\right.$ in one study $\left.{ }^{7}\right)$ regard their episodes as affected by mental stress, but this may less often be the case in children.

In the management of children the first step should be to establish whether the nocturnal episodes are the only symptoms or whether they form part of a wider disturbance. Possible areas of stress at home and school should be explored. Marital discord, psychiatric disorder in one or both parents, and excessive pressure to succeed at school are perhaps the most common background factors; sometimes these may respond to brief counselling. A severe problem which fails to respond to simple measures justifies referral to a child-and-family guidance clinic or to a child psychiatrist. 
If the sleepwalking and night terrors are isolated problemsand in childhood this is most often the case-the reasons for parental anxiety should be determined. Reassurance may be given about the usually benign long-term outcome, but symptomatic advice will often be helpful. Establishing regular bedtime routines and avoiding frightening television programmes may help prevent sleepwalking and night terrors. "Proofing" the environment to prevent accidental injury to sleepwalkers is well worth while. As many as $24 \%$ of adult sleepwalkers have reported injuring themselves, ${ }^{7}$ and though the risk may be less in childhood it is not negligible. The view of the sleepwalking episode as an acted-out dream has been challenged, ${ }^{8}$ but nevertheless the parents should be encouraged to talk with the child and to share and if possible understand his or her anxieties about the episodes and other possible stresses. Finally, in cases of frequent sleepwalking the risk of injury may justify a trial of treatment with diazepam. ${ }^{8}$

${ }^{1}$ Bixler EO, Kales A, Soldatos CR, Kales JD, Healey S. Prevalence of sleep disorders in the Los Angeles metropolitan area. Am F Psychiatry 1979; 136: $1257-62$.

2 Anders TF, Weinstein P. Sleep and its disorders in infants and children: a review. Pediatrics 1972;50:312-24.

${ }^{3}$ Kales A, Jacobson A, Paulson MJ, Kales JD, Walter RD. Somnambulism: psychophysiological correlates I. All-night EEG studies. Arch Gen Psychiatry 1966;14:586-94.

${ }^{4}$ Bakwin H. Sleep-walking in twins. Lancet 1970 ;ii:446-7.

5 Kales A, Soldatos CR, Bixler EO, et al. Hereditary factors in sleepwalking and night terrors. Br $\mathcal{F}$ Psychiatry 1980;137:111-8.

${ }^{6}$ Kales A, Paulson MJ, Jacobson A, Kales D. Somnambulism: psychophysiological correlates II. Psychiatric interviews, psychological testing and discussion. Arch Gen Psychiatry 1966;14:595-604.

Kales JD, Humphrey FJ, Martin ED, et al. Clinical characteristics of patients with sleepwalking: further studies. Sleep Research 1978;7:192.

${ }^{3}$ Guilleminault C, Anders TF. Sleep disorders in children. Adv Pediatr $1976 ; 22: 151-74$.

\section{Born again and live longer?}

As the "born-again" evangelical movement swept through the United States it gathered up both of the recent leading Presidential candidates. We are also told that Americans are living longer. ${ }^{1}$ Are the two phenomena related, and if so, should survival be calculated from the first or the most recent birth? So far neither "born-again" nor any similar improvement in longevity in middle age seems to have reached Britain. If they did, not only would campaigning politicians need to take notice but so also would the army of demographers, statisticians, registrars of births, marriages, and deaths-and in particular the Registrar General himself, who sits in solitary splendour at his command post in the Office of Population Censuses and Surveys armed only with his swaggerstick and adding machine.

Over the one and a half centuries of his command the annual reports from the Registrar General have always been of a special quality among Government statistics. The money supply may be miscalculated by the odd thousand million pounds, or figures for exports, unemployment, or cost of living may need to be recalculated or readjusted; but the citizens of England and Wales have rested content that each and every one of them would be mentioned in the annual dispatches from the Registrar General, once at birth and once at death. These vital statistics, extending back so many years, are not just crude estimates but real numbers, counted laboriously to six digits and more of unquestioned accuracy, and truly the envy of the world.
Could such an established tradition be mistaken? Is it not time that this early Victorian rationalism was replaced by a new policy with a laid-back approach to metaphysics? All the current publications assume, naively, that we are all born once each, and then at exactly the same early age, that we all age uniformly according to the number of calendar years elapsed, and that life is finite and measurable and extends only as far as death, which occurs to all of us, and then once only. If divorce and multiple remarriages were established in the 1940s and 1950 s, resuscitation from sudden death became commonplace in the 1960 s and 1970 s, so perhaps multiple rebirth will be the pattern of the 1980s. If so, the Registrar General must reconsider his limited range of publications on numbers of births, marriages, and deaths, and age at death, and extend them in the interests of comprehensiveness and commercial profit. His admirable decennial supplements on occupational and area mortality and on cancer should be joined by others on age since last reincarnation, survival after first death, frequency of rebirth, aeons in purgatory, and many more. To save having to retrain him and his staff-officers, he could be helped by a specialist Civil-Service task-force of mediums, spiritualists, and clairvoyants; these could be usefully seconded from the Treasury.

Meanwhile what evidence is there that a spiritual rebirth or a virtuous life leads to longer survival on earth? Unfortunately neither the Registrar General in his decennial censuses and his death certificates nor the numerous designers of cohort studies of risk factors have bothered to measure the state of grace of the subjects whose survival they were plotting. The nearest approaches to this problem are in studies of occupation and mortality. While occupation may not relate direct to virtue, there is some relation to poverty, chastity, and obedience. The Registrar General's decennial supplements on occupational mortality ${ }^{2-4}$ have always shown higher mortality in single than married persons. It is not too surprising, therefore, that a comparison ${ }^{2}$ of Church of England clergy with Roman Catholic priests showed a higher mortality in the latter, whose mortality rates were no better than average for all employed men. Single women in religious orders had mortality rates that were only slightly better than average for single women in the $1961^{3}$ report and considerably worse in 1970-2. ${ }^{4}$ Similarly obedience does not identify either the police or the armed Forces as at low risk; if anything the reverse.

What about poverty? Social-class gradients in mortality suggest that it, too, may be harmful, while in England and Wales the lower mortality of the clergy compared with other professions over the past 50 years seems to be disappearing at the same time as their comparative living standards may have dropped. On the other hand, a series of studies in the United States suggest that Baptist, Lutheran, Presbyterian, and Episcopalian clergymen have lower death rates than those for white clergymen and all white males generally. ${ }^{5-9}$ Rational explanations for these differences and trends might be sought in the way clergy and others are selected and in their smoking and drinking habits and accident proneness. The indications, however, are that those who are securing their treasure in heaven rather than on earth may not live much longer; perhaps the years pass more slowly. Fortunately, even if our politicians were to be born again before each election their term of office on earth would still be limited.

${ }^{1}$ Havlik RJ, Feinleib M, eds. Proceedings of the conference on the decline in coronary heart disease mortality. Washington: US Department of Health, Education and Welfare, 1979. (NIH 79-1610.)

2 Registrar General. Decennial supplement for England and Wales 1951. Occupational mortality. London: HMSO, 1958. 